\title{
One-step Nucleic Acid Amplification Can Identify Sentinel Node-negative Breast Cancer Patients With Excellent Prognosis
}

\author{
KENZO SHIMAZU, TOMOHIRO MIYAKE, JUN OKUNO, YASUTO NAOI, TOMONORI TANEI, \\ MASAFUMI SHIMODA, NAOFUMI KAGARA, SEUNG JIN KIM and SHINZABURO NOGUCHI
}

Department of Breast and Endocrine Surgery, Osaka University Graduate School of Medicine, Osaka, Japan

\begin{abstract}
Background/Aim: One-step nucleic acid amplification (OSNA) is a newly developed procedure for detection of node metastasis by targeting CK19 mRNA. This study aimed to compare the prognosis of ER-positive/HER2negative (ER+/HER2-) breast cancer patients with negative sentinel lymph node (SLN), as determined by OSNA with that determined by pathology. Patients and Methods: A total of 508 patients who underwent breast surgery and SLN biopsy were enrolled. Of 263 patients with negative SLN by OSNA (osNO), 239 were treated with endocrine therapy alone (osNO-ET), and of 107 with negative SLN by pathology $(p N O), 103$ were treated with endocrine therapy alone ( $p N O$ ET). Results: Distant relapse-free survival (DRFS) of osNOET group $(99.5 \%$ at 6 years) was significantly better $(p=0.044)$ than that of $p N O-E T$ group. Multivariate analysis revealed that osNO was significantly associated $(p=0.019)$ with favorable DRFS. Conclusion: ER+/HER2- breast cancer patients with negative SLN by OSNA show an excellent prognosis with endocrine therapy alone.
\end{abstract}

Axillary nodal status is the most significant independent prognostic factor for breast cancer. Currently, sentinel lymph node biopsy (SLNB) has become the standard procedure for staging axillary nodal status of patients with early invasive breast cancer (1-5). The advantages of SLNB in breast cancer patients include enhanced pathological examination of a small number of sentinel lymph nodes (SLN), which permits more frequent detection of micrometastasis and isolated tumor cells (ITC) by means of pathological examination with serial sectioning and/or immunohistochemistry (IHC). In fact, some studies have reported that initially node-negative patients with

Correspondence to: Kenzo Shimazu, MD, Department of Breast and Endocrine Surgery, Osaka University Graduate School of Medicine, 22-E10 Yamadaoka, Suita, Osaka 565-0871, Japan. Tel: +81 668793772, Fax: +81 668793779, e-mail: kshimazu@ onsurg.med.osaka-u.ac.jp

Key Words: Breast cancer, sentinel lymph node, prognosis, one-step nucleic acid amplification. conventional pathological examination turned out to be nodepositive with more extensive pathological assessment (6). However, such an exhaustive examination of each SLN is unfeasible in daily clinical practice.

In the meantime, the one-step nucleic acid amplification (OSNA) has been developed as a rapid procedure for detecting lymph node (LN) metastasis by targeting cytokeratin 19 (CK19) mRNA (7). OSNA can be completed within 30-40 min, making it suitable as an intra-operative procedure for detecting SLN metastasis (8-12). Since an entire LN can be examined by OSNA, unlike by routine pathological examination which examines only a few representative sections from each $\mathrm{LN}$, micrometastasis is considered less likely to be missed by OSNA than by a routine pathological examination. In fact, comparison of for the detection rates of LN metastasis by OSNA and by pathology (step-section analysis with immunohistochemistry) shows a slightly higher rate of detection by OSNA than by pathology, suggesting that OSNA can detect some micrometastases missed by pathology (13-15).

Although some aspects remain controversial, a large body of evidence seems to indicate that micrometastasis of LN, but not of ITCs, is of significant prognostic importance $(6,16-$ 18). We, therefore, hypothesized that patients with negative SLN examined by OSNA (osN0) would have a better prognosis than those with negative SLN assessed by pathology (pN0). The aim of this study was, thus, to compare the prognosis of osN0 and $\mathrm{pNO}$ patients.

\section{Patients and Methods}

Patient population. This retrospective study included 508 consecutive patients with estrogen receptor (ER)-positive, human epidermal growth factor receptor (HER2)-negative, and SLNnegative invasive breast cancers (T1-2N0) who underwent breast surgery (breast conserving surgery or mastectomy) with SLNB between July 2008 and May 2015. For examination of SLN metastasis, OSNA or pathology was used at the physician's discretion with one of the methods described below. ALNs of every patient were preoperatively examined by ultrasonography (US). When ALN metastasis was suspected, fine needle aspiration 
cytology (FNAC) was performed and the patients with cytologyproven ALN metastasis were excluded from the study. This study was approved by the Ethical Review Board of Osaka University Hospital (approval number:12423-4).

Sentinel lymph node biopsy. All patients underwent SLN biopsy with a combination of patent blue and indocyanine green and/or radiocolloid (technetium 99m tin-colloid). The methodology of SLN biopsy has been described in detail in our previous studies (3-5). SLN (blue) was defined as a lymph node partially or completely stained by blue dye or directly connected to a blue-stained afferent lymphatic tract. SLN (radiocolloid) was defined as a lymph node with ex vivo radioactivity (counts per second) measuring $400 \%$ or more than that of the axillary background.

OSNA. The method for OSNA has been described previously in more detail $(10,12)$. Briefly, after removal of a very thin slice $(1 \mathrm{~mm})$ from the middle of each SLN for pathological examination, the remaining LN slice was homogenized in $4 \mathrm{ml}$ of Lynorhag lysis buffer (Sysmex, Kobe, Japan), $\mathrm{pH} 3.5$, and centrifuged briefly at room temperature, followed by assessment of two microliters of the supernatant in an RD-100i system using reverse transcription loop-mediated isothermal amplification (RT-LAMP). The results were reported according to the manufacturer's instructions as negative $\left(<2.5 \times 10^{2}\right.$ copies $\left./ \mu \mathrm{l}\right)$, + positive $\left(\geq 2.5 \times 10^{2}\right.$ and $<5.0 \times 10^{3}$ copies $/ \mu 1=$ micrometastasis $)$, ++ positive $\left(\geq 5.0 \times 10^{3}\right.$ copies $/ \mu \mathrm{l}=$ macrometastasis), or $+\mathrm{i}$ (inhibited in the regular sample and $\geq 2.5 \times 10^{2}$ copies $/ \mu$ in the diluted sample) (7). Patients classified as $+\mathrm{i}$ were also considered positive. The quantity of $\mathrm{LN}$ available for one OSNA reaction weighed between 50 $\mathrm{mg}$ and $600 \mathrm{mg}$. If the removed SLN weighed more than $600 \mathrm{mg}$, the node was divided into two sections for separate assays by OSNA.

Pathological examination. A 2-mm thick slice was cut from the middle of each SLN for intraoperative frozen section examination. The remainders of the SLN as well as the slice subjected to frozen section examination were fixed in $10 \%$ buffered formalin. The remainder of the SLN was sectioned into 2-mm slices, and embedded in paraffin. The remaining slices subjected to frozen section were also embedded in paraffin. The paraffin sections (4 $\mu \mathrm{m})$ of these SLNs were subjected to Hematoxylin Eosin (HE) staining and immunohistochemistry with an anti-cytokeratin antibody (AE1/3) (Nichirei, Tokyo, Japan) as described previously (3-5). For the present study, micro- and macro-metastases, but not isolated tumor cells (ITCs), were classified as metastases. The thin slice $(1 \mathrm{~mm})$ cut from the SLN before analysis by OSNA was also examined by HE staining.

Determination of ER, progesterone receptor (PR), Ki67 and HER2. ER, $\mathrm{PR}$, and Ki67 expression in tumor tissues was immunohisto-chemically examined with a previously described method (19). ER and PR were defined as positive when $10 \%$ or more of the tumor cells stained immunohistochemically positive. Ki67 was defined as positive when $20 \%$ or more of tumor cells stained positive. HER2 was determined immunohistochemically and/or by means of fluorescence in situ hybridization (FISH). When a tumor showed +3 immunostaining or the FISH ratio was $\geq 2.0$, it was considered HER2 positive.

Adjuvant therapy. Every patient was treated with adjuvant endocrine therapy (tamoxifen or tamoxifen plus LH-RH agonist for premenopausal women, and tamoxifen or aromatase inhibitor for postmenopausal women), and the decision as to adjuvant chemotherapy was made by the physician concerned, taking into consideration age, tumor size, histological grade and Ki67 ( $\geq 20 \%)$. Every patient treated with breast conserving surgery received radiation therapy (50 Gy) to the whole breast and none of the patients treated with mastectomy was given radiation therapy.

Statistical analysis. JMP_14.0 (SAS Institute Inc., Cary, NC, USA) software was used for the statistical analyses in this study. Chisquare test and Fisher's exact test were used for comparing the clinicopathological factors of two groups. Distant relapse-free survival (DRFS) was defined as the time from surgery to distant recurrence of breast cancer. Disease-free survival (DFS) events included ipsilateral breast cancer recurrence, local/regional recurrence, distant recurrence, or death from any cause. Overall survival (OS) was defined as the time from surgery to death from any cause. DRFS, DFS, and OS rates were estimated using the Kaplan-Meier survival curve and compared for the two groups with a log-rank test. Multivariate analysis of various parameters associated with DRFS was conducted using Cox's proportional hazard regression models. A $p$-value of $<0.05$ was considered significant.

\section{Results}

Patients analyzed. SLNs of 508 patients with ER+/HER2- and clinically node-negative invasive breast cancers (T1-2NOM0) were subjected to OSNA (376 patients) or pathological examination (132 patients) at the physician's discretion. SLN metastasis was found in 113 patients $(30.1 \%)$ by OSNA and 25 patients $(18.9 \%)$ by pathological examination (Figure 1). Detection of positivity for SLN metastasis by OSNA was significantly higher than that by pathology $(p=0.014)$. Of the 113 OSNA-positive patients, 71 were assessed as + positive (=micrometastasis), 37 were assessed as ++ positive (=macrometastasis) and 5 were assessed as $+\mathrm{i}$. Of the 25 pathology-positive patients, 16 were diagnosed as macrometastasis and 9 were diagnosed as micrometastasis.

Of the 263 patients with negative SLN detected by OSNA (osN0), 239 were treated with adjuvant endocrine therapy alone (osN0-ET group), and of the 107 patients with negative SLN identified by pathology (pN0), 103 were treated with adjuvant endocrine therapy alone (pNO-ET group) (Figure 1). The osN0-ET group included only one patient with micrometastasis detected histologically in a 1-mm slice cut from the center of an SLN. The clinicopathological characteristics of the osNO-ET group and pNO-ET group are shown in Table I. There was no significant difference in any clinicopathological characteristics between the two groups. There were also no differences in the number of removed and examined SLNs between the two groups. The median followup was 60 months (range $=12-120$ months).

Prognosis of osNO or pNO patients. DRFS, DFS, and OS of the patients in the osN0-ET group and pN0-ET group are shown in Figure 2. DRFS was significantly better $(p=0.044)$ 


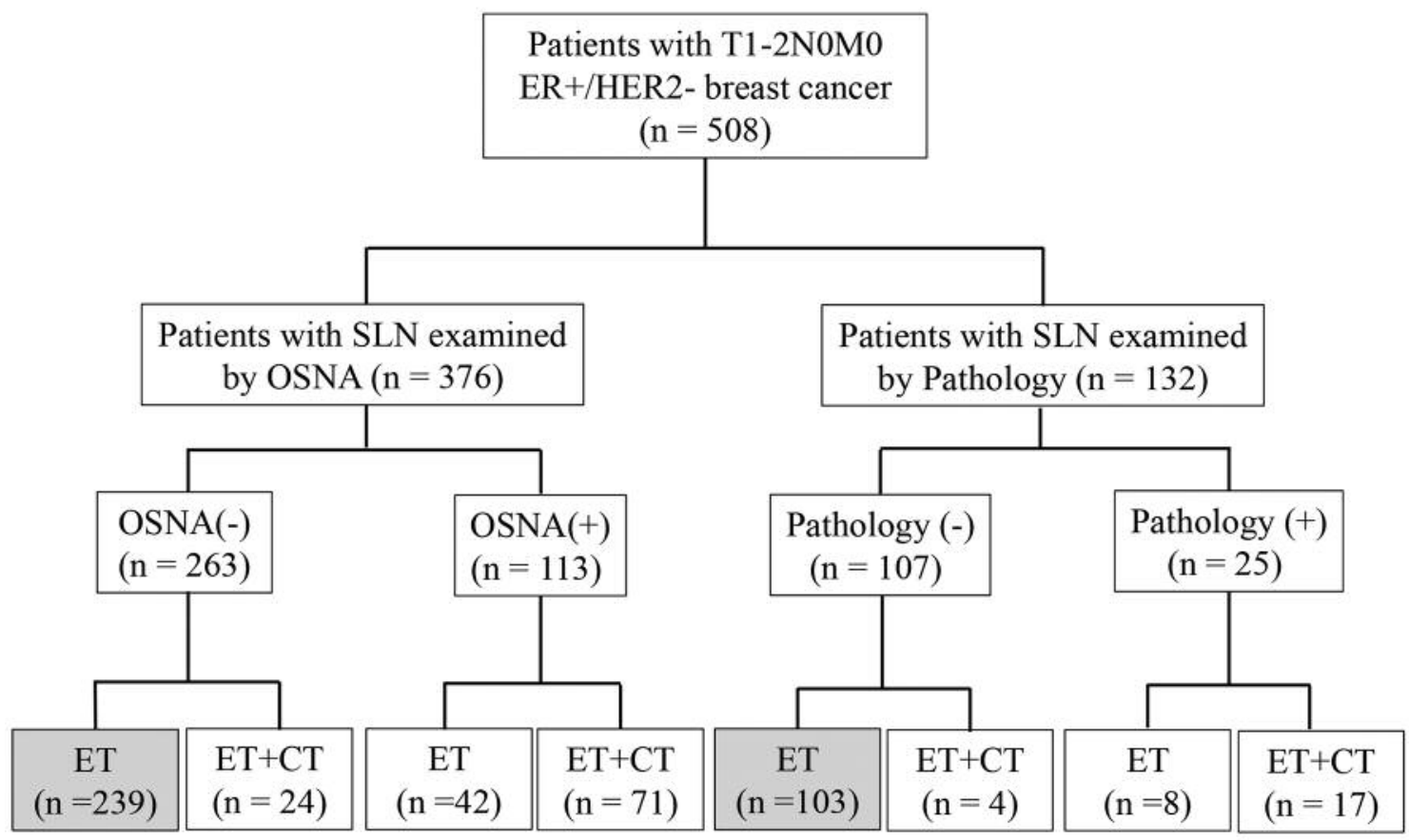

Figure 1. Flowchart of patient selection. ER: Estrogen receptor; HER2: human epidermal growth factor receptor 2; OSNA: one-step nucleic acid amplification; ET: endocrine therapy; CT: chemotherapy.

in the osN0-ET group than the pNO-ET group (Figure 2A), and the osN0-ET group tended to show a better DFS than the pNO-ET group although the difference was not statistically significant (Figure 2B). OS of the two groups was similar (Figure 2C). Multivariate analysis revealed that osNO and positive progesterone receptor were significantly associated with favorable DRFS ( $p=0.019$ and $p=0.042$, respectively) (Table II).

\section{Discussion}

Several studies have compared SLN positivity detected by OSNA and pathology $(13-15,20)$. In the studies reported by the other investigators listed in Table III, an entire SLN was examined for detection of SLN metastasis by OSNA or by pathology using step sections with immunohistochemistry for cytokeratins. All five studies including ours, found that the ratio of SLN positivity detected by OSNA was higher than that detected by pathology, and two studies showed a statistically significant difference. In addition, when all the studies were combined, a statistically significant difference in SLN positivity was observed between OSNA and pathology $(p=0.0050)$. Interestingly, Santaballa et al. reported a significant difference $(p=0.0007)$ in positivity for micrometastasis between OSNA $(11.0 \%)$ and pathology (3.6\%), but not in macrometastasis (16.5\% and $20.1 \%$, respectively) (14). Taken together, these results seem to suggest that OSNA is less likely to miss micrometastasis than pathology, which has an inherent risk of missing micrometastasis between the cut surfaces of an SLN used for pathological examination.

Until now, two studies have reported on the relationship between OSNA and prognosis. Peg et al. found that the total tumor load (TTL; defined as the total number of CK19 mRNA copies in all positive SLNs) significantly correlated with DFS and OS and a low-risk group could be differentiated from a high-risk group by using a TTL cut-off value of $2.5 \times 10^{4}(21)$. Osako et al. reported that osN0 patients showed an excellent prognosis (5-year DRFS $=98.0 \%$ ) which is consistent with our results (22). However, no reported studies have compared prognosis for osN0 and pN0 patients. In the study presented here, osN0-ET patients showed a significantly better DRFS than did pNO-ET patients. It is speculated that a significant proportion of SLN micrometastases could not be identified (i.e., occult metastases) by routine pathological examination, but could by OSNA. Thus, the reason for the better DRFS of the osN0-ET group than the pNO-ET group is thought to be attributable to inclusion of a higher proportion of patients with SLN occult metastasis in the latter group. Weaver et al. reported that meticulous multistep section analysis revealed occult metastases (isolated tumor cells $(11.1 \%)$, micrometastases 
Table I. Clinicopathological characteristics of patients entered in this study.

\begin{tabular}{|c|c|c|c|}
\hline Characteristic & $\begin{array}{l}\text { osN0-ET group } \\
\quad(\mathrm{n}=237)\end{array}$ & $\begin{array}{l}\text { pN0-ET group } \\
\quad(\mathrm{n}=103)\end{array}$ & $p$-Value \\
\hline \multicolumn{4}{|l|}{ Age } \\
\hline Median & $58(29-90)$ & $56(25-85)$ & 0.35 \\
\hline \multicolumn{4}{|l|}{ Menopausal status } \\
\hline Premenopausal & $100(42.6 \%)$ & $43(41.7 \%)$ & 0.95 \\
\hline Postmenopausal & $133(56.6 \%)$ & $58(56.3 \%)$ & \\
\hline Unknown & $4(1.7 \%)$ & $2(1.9 \%)$ & \\
\hline \multicolumn{4}{|l|}{ Tumor size $(\mathrm{cm})$} \\
\hline Median (range) & $1.4(0-5.0)$ & $1.5(0-5.0)$ & 0.34 \\
\hline Mean & $1.5 \pm 0.7$ & $1.6 \pm 0.9$ & \\
\hline Unknown & $8(3.4 \%)$ & $4(3.9 \%)$ & \\
\hline \multicolumn{4}{|l|}{$\mathrm{T}$} \\
\hline $\mathrm{T} 1$ & $206(86.9 \%)$ & $81(78.6 \%)$ & 0.065 \\
\hline $\mathrm{T} 2$ & $31(13.1 \%)$ & $21(20.4 \%)$ & \\
\hline Unknown & $0(0 \%)$ & $1(1.0 \%)$ & \\
\hline \multicolumn{4}{|l|}{ PR } \\
\hline Positive & $199(84.0 \%)$ & $88(85.4 \%)$ & 0.73 \\
\hline Negative & $38(16.0 \%)$ & $15(14.6 \%)$ & \\
\hline \multicolumn{4}{|l|}{ Type } \\
\hline IDC & $200(84.7 \%)$ & $86(83.5 \%)$ & 0.95 \\
\hline ILC & $17(7.2 \%)$ & $8(8.7 \%)$ & \\
\hline Special types & $19(8.0 \%)$ & $9(5.3 \%)$ & \\
\hline \multicolumn{4}{|l|}{ Histological Grade } \\
\hline Grade 1 & $141(60.8 \%)$ & $68(66.0 \%)$ & 0.39 \\
\hline Grade 2 & $84(36.2 \%)$ & $31(30.1 \%)$ & \\
\hline Grade 3 & $5(1.9 \%)$ & $4(3.9 \%)$ & \\
\hline Unknown & $2(0.9 \%)$ & $0(0 \%)$ & \\
\hline \multicolumn{4}{|l|}{ Surgery } \\
\hline Breast conserving surgery & $144(60.8 \%)$ & $55(53.3 \%)$ & 0.21 \\
\hline Mastectomy & $93(39.2 \%)$ & $48(46.6 \%)$ & \\
\hline \multicolumn{4}{|c|}{ Adjuvant endocrine therapy } \\
\hline Tamoxifen & $76(31.8 \%)$ & $32(31.1 \%)$ & 0.82 \\
\hline Aromatase inhibitor & $126(52.7 \%)$ & $53(51.5 \%)$ & \\
\hline Tamoxifen+LH-RHa & $35(14.6 \%)$ & $18(17.5 \%)$ & \\
\hline
\end{tabular}

osN0: Patients with SLN-negative examined by One-step nucleic acid amplification (OSNA); ET: endocrine therapy; pN0: patients with SLNnegative examined by pathology; PR: Progesterone receptor; IDC: invasive ductal cancer; ILC: invasive lobular cancer; LH-RHa: LH-RH agonist.

(4.4\%), and macrometastases (0.4\%)) in SLNs initially classified as negative by a routine histological examination, and these previously occult metastases had a small but significant impact on OS, DFS, and distant disease-free interval (16). It has been reported that $9-32 \%$ of patients with negative LNs, identified by various pathological methods, were found to have occult metastasis following meticulous examination (6). This indicates that a significant proportion of patients with SLN metastasis may be underdiagnosed as being without SLN metastasis by routine histological examination. On the other hand, it can be expected that osN0 patients are less likely to harbor occult metastasis since the entire SLN is examined by OSNA.
Table II. Multivariate analysis of prognostic parameters for DRFS.

\begin{tabular}{llc}
\hline & \multicolumn{2}{c}{ Multivariate analysis } \\
\cline { 2 - 3 } Parameters & Hazard Ratio (95\%CI) & $p$-Value \\
\hline $\begin{array}{l}\text { Tumor size } \\
\quad>2 \mathrm{~cm} v s . \leq 2 \mathrm{~cm}\end{array}$ & $2.10(0.40-10.02)$ & 0.36 \\
$\begin{array}{l}\text { Progesterone receptor } \\
\quad \text { Negative } v \text {. Positive }\end{array}$ & $5.08(1.07-25.87)$ & 0.042 \\
$\begin{array}{l}\text { Ki67 LI } \\
\quad \geq 20 \% \text { vs. }<20 \%\end{array}$ & $2.14(0.37-12.63)$ & 0.38 \\
$\begin{array}{l}\text { Menopausal status } \\
\text { Post. } v s . \text { Pre. }\end{array}$ & $1.83(0.31-14.50)$ & 0.51 \\
$\begin{array}{l}\text { Method for N0 determination } \\
\text { pN0 vs. osN0 }\end{array}$ & $6.06(1.35-33.32)$ & 0.019 \\
\hline
\end{tabular}

DRFS: Distant relapse-free survival; osN0: patients with SLN-negative examined by one-step nucleic acid amplification (OSNA); pN0: patients with SLN-negative examined by pathology; Pre: premenopausal; Post: postmenopausal.

Another interesting finding of this study is the attainment of an excellent prognosis for the osN0-ET group, which is equivalent to that for patients at low-risk identified by Oncotype DX in the Trial Assigning IndividuaLized Options for Treatment (Rx), the TAILORx study (23). Only $9.1 \%$ of patients with ER+/HER2- and osN0 breast cancer in our study were treated with adjuvant chemotherapy, the indication for which was determined essentially according to the histological grade and Ki67. Thus, the patients treated with adjuvant chemotherapy showed a higher proportion of grade III tumors and Ki67-high tumors (Table IV). Chemotherapy could be avoided for as many as $90.9 \%$ of the patients with ER-positive/HER2-negative/osN0 breast cancer, who attained an excellent prognosis. According to meta-analysis on Oncotype DX in actual practice (24), this genomic test could avoid chemotherapy for 55.1-78.7\% (pooled mean, $72.0 \%$ ) of ER+/HER2- and pN0 patients. More recently, the TAILORx study reported that $86 \%$ of the patients with ER+/HER2- and pN0 breast cancer can be spared adjuvant chemotherapy (25). Even when taking into consideration the fact that SLN positivity is higher (Table III) when detected by OSNA than by pathology, the final proportion of ER+/HER2- and clinically node-negative patients for whom adjuvant chemotherapy can safely be avoided is thought to be similar for OSNA and Oncotype DX. These results seem to suggest the possibility that an accurate determination of SLN status using OSNA may be clinically useful for the selection of patients with an excellent prognosis who can be safely treated with adjuvant endocrine therapy alone, and the capability of this diagnostic assay to select such patients may be no worse than that of Oncotype DX. 


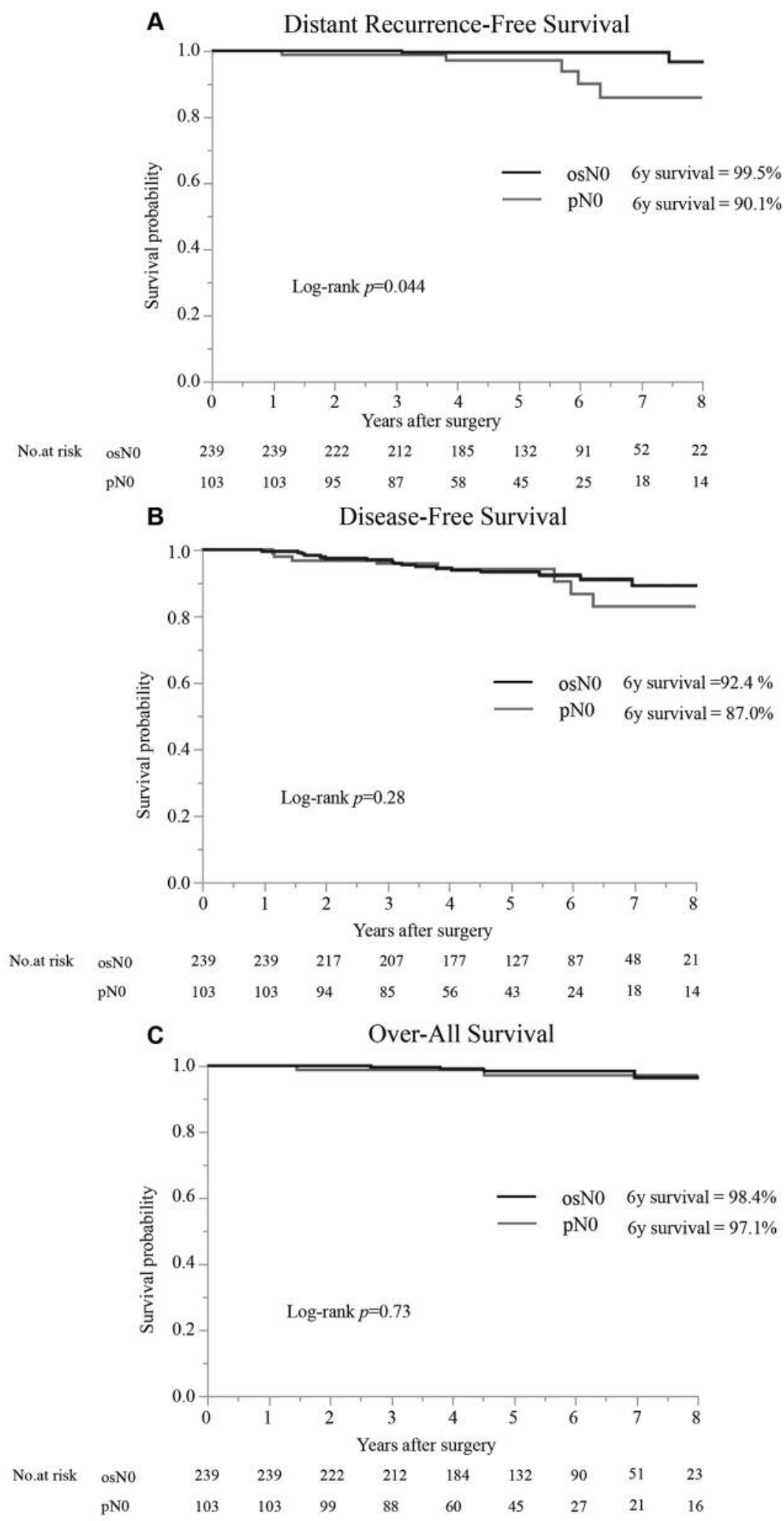

Figure 2. Kaplan-Meier analyses of relapse-free, disease-free and overall survival. A) Results of Kaplan-Meier analyses of distant relapse-free survival across the two groups. B) Results of Kaplan-Meier analyses of disease-free survival across the two groups. C) Results of Kaplan-Meier analyses of overall survival across the two groups. osNO, the patients with negative SLN examined by one-step nucleic acid amplification (OSNA); pNO: patients with negative SLN examined by pathology. 
Table III. Summary of studies comparing sentinel lymph node metastasis detected by OSNA and pathology.

\begin{tabular}{|c|c|c|c|c|c|}
\hline & \multicolumn{2}{|c|}{ OSNA } & \multicolumn{2}{|c|}{ Pathology } & \multirow[b]{2}{*}{$p$-Value } \\
\hline & No. of pt & Positivity & No. of $\mathrm{pt}$ & Positivitya & \\
\hline Our study & 376 & $30.1 \%$ & 132 & $18.9 \%$ & 0.014 \\
\hline Castellano (13) & 110 & $29.1 \%$ & 169 & $27.2 \%$ & n.s. \\
\hline Santaballa (14) & 164 & $27.4 \%$ & 244 & $23.8 \%$ & n.s. \\
\hline Ruano (15) & 148 & $40.5 \%$ & 153 & $28.1 \%$ & 0.023 \\
\hline Godey (20) & 258 & $24.4 \%$ & 355 & $23.4 \%$ & n.s. \\
\hline Total & 1056 & $29.6 \%$ & 1053 & $24.2 \%$ & 0.0050 \\
\hline
\end{tabular}

aPositivity: macrometastasis and micrometastasis, but not isolated tumor cells, were considered to indicate positivity. For all studies, pathological examination included immunohistochemistry with an anti-cytokeratin antibody.

In conclusion, patients with ER+/HER2- and osN0 breast cancer treated with endocrine therapy alone showed better DRFS than those with ER+/HER2- and pN0 breast cancer. SLN micrometastasis missed by a routine pathological examination, but not by OSNA is speculated to have a negative impact on this finding. However, since our results are based on the findings of a retrospective study, they need to be validated by a prospective study including a larger number of patients.

\section{Conflicts of Interest}

K.S. has received honoraria from AstraZeneca. Y.N. has received honoraria from Sysmex, and has received research funding from AstraZeneca on the other studies. S.J.K. has received honoraria from AstraZeneca, Takeda, Novartis, Pfizer and Sysmex. S.N. has been an advisor for AstraZeneca, Novartis and Taiho, has received honoraria from Sysmex, AstraZeneca, Chugai, Nippon Kayaku, Novartis and Takeda, and has received research funding from Sysmex, AstraZeneca, Chugai, Daiichi-Sankyo, Eisai, Nippon Kayaku, Novartis, Ono, Pfizer, Taiho and Takeda on the other studies. S.N. and Y.N. hold the joint patents with Sysmex on subjects not related to this study. The other Authors do not declare any conflict of interest related to this study. This study was not supported by any funding sources.

\section{Authors' Contributions}

Conception and design: Shimazu K, Noguchi S; Collection and assembly of data: All authors; Data analysis and interpretation: Shimazu K, Noguchi S, Miyake T; Final approval of manuscript: All authors.

\section{References}

1 Giuliano AE, Kirgan DM, Guenther JM and Morton DL: Lymphatic mapping and sentinel lymphadenectomy for breast cancer. Ann Surg 220(3): 391-398, 1994. PMID: 8092905

2 Veronesi U, Paganelli G, Viale G, Luini A, Zurrida S, Galimberti V, Intra M, Veronesi P, Maisonneuve P, Gatti G, Mazzarol G, De Cicco C, Manfredi G and Fernandez JR: Sentinel-lymph-node
Table IV. Clinicopathological characteristics of osNO patients according to treatment.

\begin{tabular}{|c|c|c|c|}
\hline Characteristic & $\begin{array}{l}\text { osN0-ET } \\
\text { group } \\
(n=237)\end{array}$ & $\begin{array}{c}\text { osN0-ET+CT } \\
\text { group } \\
(\mathrm{n}=23)\end{array}$ & $p$-Value \\
\hline \multicolumn{4}{|l|}{ Age } \\
\hline Median & $58(29-90)$ & $51(26-67)$ & n.s. \\
\hline \multicolumn{4}{|l|}{ Menopausal status } \\
\hline Premenopausal & $100(42.6 \%)$ & $11(47.8 \%)$ & \multirow[t]{3}{*}{ n.s. } \\
\hline Postmenopausal & $133(56.6 \%)$ & $12(52.2 \%)$ & \\
\hline Unknown & $4(1.7 \%)$ & $0(0 \%)$ & \\
\hline \multicolumn{4}{|l|}{ Tumor size $(\mathrm{cm})$} \\
\hline Median (range) & $1.4(0-5.0)$ & $1.6(0.7-4.7)$ & \multirow[t]{3}{*}{$<0.05$} \\
\hline Mean & $1.5 \pm 0.7$ & $1.9 \pm 0.9$ & \\
\hline Unknown & $8(3.4 \%)$ & $0(0 \%)$ & \\
\hline \multicolumn{4}{|l|}{$\mathrm{T}$} \\
\hline $\mathrm{T} 1$ & $206(86.9 \%)$ & $15(65.2 \%)$ & \multirow[t]{2}{*}{$<0.01$} \\
\hline $\mathrm{T} 2$ & $31(13.1 \%)$ & $8(34.8 \%)$ & \\
\hline \multicolumn{4}{|l|}{ PR } \\
\hline Positive & $199(84.0 \%)$ & $19(82.6 \%)$ & \multirow[t]{2}{*}{ n.s. } \\
\hline Negative & $38(16.0 \%)$ & $4(17.4 \%)$ & \\
\hline \multicolumn{4}{|l|}{ Type } \\
\hline ILC & $17(7.2 \%)$ & $2(8.6 \%)$ & \multirow[t]{3}{*}{ n.s. } \\
\hline IDC & $200(84.7 \%)$ & $20(87.0 \%)$ & \\
\hline Special type & $19(8.0 \%)$ & $1(4.3 \%)$ & \\
\hline \multicolumn{4}{|l|}{ Histological Grade } \\
\hline Grade 1 & $141(60.8 \%)$ & $3(13.0 \%)$ & \multirow[t]{4}{*}{$<0.0001$} \\
\hline Grade2 & $84(36.2 \%)$ & $8(34.8 \%)$ & \\
\hline Grade3 & $5(1.9 \%)$ & $12(52.2 \%)$ & \\
\hline Unknown & $2(0.9 \%)$ & $0(0 \%)$ & \\
\hline \multicolumn{4}{|l|}{ Ki67LI } \\
\hline$<20 \%$ & $94(39.3 \%)$ & $3(13.0 \%)$ & \multirow[t]{3}{*}{$<0.05$} \\
\hline$\geq 20 \%$ & $128(53.6 \%)$ & $17(73.9 \%)$ & \\
\hline Unknown & $17(7.1 \%)$ & $3(13.0 \%)$ & \\
\hline \multicolumn{4}{|l|}{ Surgery } \\
\hline Partial & $144(60.8 \%)$ & $15(65.2 \%)$ & \multirow[t]{2}{*}{ n.s. } \\
\hline Total & $93(39.2 \%)$ & $8(34.8 \%)$ & \\
\hline
\end{tabular}

osN0: Patients with SLN-negative examined by One-step nucleic acid amplification (OSNA); ET: endocrine therapy; CT: chemotherapy; PR: progesterone receptor; IDC: invasive ductal cancer; ILC: invasive lobular cancer. 
biopsy as a staging procedure in breast cancer: Update of a randomised controlled study. Lancet Oncol 7(12): 983-990, 2006. PMID:17138219, DOI:10.1016/S1470-2045(06)70947-0

3 Shimazu K, Tamaki Y, Taguchi T, Takamura Y and Noguchi S: Comparison between periareolar and peritumoral injection of radiotracer for sentinel lymph node biopsy in patients with breast cancer. Surgery 131(3): 277-286, 2002. PMID:11894032

4 Shimazu K, Tamaki Y, Taguchi T, Motomura K, Inaji H, Koyama H, Kasugai T, Wada A and Noguchi S: Lymphoscintigraphic visualization of internal mammary nodes with subtumoral injection of radiocolloid in patients with breast cancer. Ann Surg 237(3): 390-398, 2003. PMID:12616124, DOI:10.1097/ 01.SLA.0000055226.89022.90

5 Shimazu K, Tamaki Y, Taguchi T, Tsukamoto F, Kasugai T and Noguchi S: Intraoperative frozen section analysis of sentinel lymph node in breast cancer patients treated with neoadjuvant chemotherapy. Ann Surg Oncol 15(6): 1717-1722, 2008.PMID: 18266040, DOI: 10.1245/s10434-008-9831-3

6 Park D, Karesen R, Naume B, Synnestvedt M, Beraki E and Sauer T: The prognostic impact of occult nodal metastasis in early breast carcinoma. Breast Cancer Res Treat 118(1): 57-66, 2009. PMID:19219629, DOI:10.1007/s10549-009-0340-2

7 Tsujimoto M, Nakabayashi K, Yoshidome K, Kaneko T, Iwase T, Akiyama F, Kato Y, Tsuda H, Ueda S, Sato K, Tamaki Y, Noguchi S, Kataoka TR, Nakajima H, Komoike Y, Inaji H, Tsugawa K, Suzuki K, Nakamura S, Daitoh M, Otomo Y and Matsuura $\mathrm{N}$ : One-step nucleic acid amplification for intraoperative detection of lymph node metastasis in breast cancer patients. Clin Cancer Res 13(16): 4807-4816, 2007. PMID: 17699859, DOI:10.1158/1078-0432.CCR-06-2512

8 Visser M, Jiwa M, Horstman A, Brink AA, Pol RP, van Diest P, Snijders PJ and Meijer CJ: Intra-operative rapid diagnostic method based on ck19 mrna expression for the detection of lymph node metastases in breast cancer. Int J Cancer 122(11): 2562-2567, 2008. PMID:18324628, DOI:10.1002/ijc.23451

9 Schem C, Maass N, Bauerschlag DO, Carstensen MH, Loning T, Roder C, Batic O, Jonat W and Tiemann K: One-step nucleic acid amplification-a molecular method for the detection of lymph node metastases in breast cancer patients; results of the german study group. Virchows Arch 454(2): 203-210, 2009. PMID:19101726, DOI:10.1007/s00428-008-0703-9

10 Tamaki Y, Akiyama F, Iwase T, Kaneko T, Tsuda H, Sato K, Ueda S, Mano M, Masuda N, Takeda M, Tsujimoto M, Yoshidome K, Inaji H, Nakajima H, Komoike Y, Kataoka TR, Nakamura S, Suzuki K, Tsugawa K, Wakasa K, Okino T, Kato Y, Noguchi S and Matsuura N: Molecular detection of lymph node metastases in breast cancer patients: Results of a multicenter trial using the one-step nucleic acid amplification assay. Clin Cancer Res 15(8): 2879-2884, 2009. PMID: 19351770, DOI: 10.1158/1078-0432.CCR-08-1881

11 Feldman S, Krishnamurthy S, Gillanders W, Gittleman M, Beitsch PD, Young PR, Streck CJ, Whitworth PW, Levine EA, Boolbol S, Han LK, Hermann R, Hoon DS, Giuliano AE, MericBernstam F and Group USOSNAACS: A novel automated assay for the rapid identification of metastatic breast carcinoma in sentinel lymph nodes. Cancer 117(12): 2599-2607, 2011. PMID:21226034, DOI:10.1002/cncr.25822

12 Teramoto A, Shimazu K, Naoi Y, Shimomura A, Shimoda M, Kagara N, Maruyama N, Kim SJ, Yoshidome K, Tsujimoto M, Tamaki Y and Noguchi S: One-step nucleic acid amplification assay for intraoperative prediction of non-sentinel lymph node metastasis in breast cancer patients with sentinel lymph node metastasis. Breast 23(5): 579-585, 2014. PMID:24973902, DOI:10.1016/j.breast.2014.05.026

13 Castellano I, Macri L, Deambrogio C, Balmativola D, Bussone R, Ala A, Coluccia C and Sapino A: Reliability of whole sentinel lymph node analysis by one-step nucleic acid amplification for intraoperative diagnosis of breast cancer metastases. Ann Surg 255(2): 334-342, 2012. PMID:21975319, DOI:10.1097/SLA.0b0 $13 \mathrm{e} 31823000 \mathrm{ed}$

14 Santaballa A, De La Cueva H, Salvador C, Garcia-Martinez AM, Guarin MJ, Lorente D, Palomar L, Aznar I, Dobon F and Bello P: Advantages of one step nucleic acid amplification (osna) whole node assay in sentinel lymph node ( $\sin$ ) analysis in breast cancer. Springerplus 2: 542, 2013. PMID:24255842, DOI:10.1186/2193-1801-2-542

15 Ruano MA, Lopez-Bonet E, Buxo M, Tuca-Rodriguez F, VilaCamps E, Alvarez E, Martin-Castillo B and Menendez JA: An improved axillary staging system using the osna assay does not modify the therapeutic management of breast cancer patients. Sci Rep 4: 5743, 2014. PMID:25034150, DOI:10.1038/ srep05743

16 Weaver DL, Ashikaga T, Krag DN, Skelly JM, Anderson SJ, Harlow SP, Julian TB, Mamounas EP and Wolmark N: Effect of occult metastases on survival in node-negative breast cancer. $\mathrm{N}$ Engl J Med 364(5): 412-421, 2011. PMID: 21247310, DOI: 10.1056/NEJMoa1008108

17 de Boer M, van Deurzen CH, van Dijck JA, Borm GF, van Diest PJ, Adang EM, Nortier JW, Rutgers EJ, Seynaeve C, MenkePluymers MB, Bult P and Tjan-Heijnen VC: Micrometastases or isolated tumor cells and the outcome of breast cancer. N Engl J Med 361(7): 653-663, 2009. PMID:19675329, DOI:10.1056/ NEJMoa 0904832

18 Andersson Y, Frisell J, Sylvan M, de Boniface J and Bergkvist $\mathrm{L}$ : Breast cancer survival in relation to the metastatic tumor burden in axillary lymph nodes. J Clin Oncol 28(17): 2868-2873, 2010. PMID:20458033, DOI: 10.1200/JCO.2009.24.5001

19 Morimoto K, Kim SJ, Tanei T, Shimazu K, Tanji Y, Taguchi T, Tamaki Y, Terada N and Noguchi S: Stem cell marker aldehyde dehydrogenase 1-positive breast cancers are characterized by negative estrogen receptor, positive human epidermal growth factor receptor type 2, and high ki67 expression. Cancer Sci 100(6): 1062-1068, 2009. PMID:19385968, DOI:10.1111/j.13497006.2009.01151.x

20 Godey F, Leveque J, Tas P, Gandon G, Poree P, Mesbah H, Lavoue V, Quillien V and Athias CB: Sentinel lymph node analysis in breast cancer: Contribution of one-step nucleic acid amplification (osna). Breast Cancer Res Treat 131(2): 509-516, 2012. PMID:21993859, DOI:10.1007/s 10549-011-1808-4

21 Peg V, Sansano I, Vieites B, Bernet L, Cano R, Cordoba A, Sancho M, Martin MD, Vilardell F, Cazorla A, Espinosa-Bravo M, Perez-Garcia JM, Cortes J, Rubio IT and Ramon YCS: Role of total tumour load of sentinel lymph node on survival in early breast cancer patients. Breast 33: 8-13, 2017. PMID:28254641, DOI:10.1016/j.breast.2017.02.011

22 Osako T, Iwase T, Ushijima M, Yonekura R, Ohno S and Akiyama F: A new molecular-based lymph node staging classification determines the prognosis of breast cancer patients. Br J Cancer 117(10): 1470-1477, 2017. PMID:28910822, DOI:10.1038/bjc.2017.311 
23 Sparano JA, Gray RJ, Makower DF, Pritchard KI, Albain KS, Hayes DF, Geyer CE, Jr., Dees EC, Perez EA, Olson JA Jr., Zujewski J, Lively T, Badve SS, Saphner TJ, Wagner LI, Whelan TJ, Ellis MJ, Paik S, Wood WC, Ravdin P, Keane MM, Gomez Moreno HL, Reddy PS, Goggins TF, Mayer IA, Brufsky AM, Toppmeyer DL, Kaklamani VG, Atkins JN, Berenberg JL and Sledge GW: Prospective validation of a 21gene expression assay in breast cancer. N Engl J Med 373(21): 2005-2014, 2015. PMID:26412349, DOI:10.1056/NEJ Moa1510764

24 Carlson JJ and Roth JA: The impact of the oncotype dx breast cancer assay in clinical practice: A systematic review and metaanalysis. Breast Cancer Res Treat 141(1): 13-22, 2013. PMID:23974828, DOI:10.1007/s 10549-013-2666-z
25 Sparano JA, Gray RJ, Makower DF, Pritchard KI, Albain KS, Hayes DF, Geyer CE Jr., Dees EC, Goetz MP, Olson JA Jr., Lively T, Badve SS, Saphner TJ, Wagner LI, Whelan TJ, Ellis MJ, Paik S, Wood WC, Ravdin PM, Keane MM, Gomez Moreno HL, Reddy PS, Goggins TF, Mayer IA, Brufsky AM, Toppmeyer DL, Kaklamani VG, Berenberg JL, Abrams J and Sledge GW Jr.: Adjuvant chemotherapy guided by a 21-gene expression assay in breast cancer. N Engl J Med 379(2): 111-121, 2018. PMID:29860917, DOI:10.1056/NEJMoa1804710

Received January 18, 2019 Revised January 30, 2019 Accepted January 31, 2019 